\title{
Treatment of Refractory Helicobacter pylori Infection-Tailored or Empirical Therapy
}

\author{
Jyh-Ming Liou ${ }^{1,2,3}$, Yi-Chia Lee ${ }^{1,2,4}$, and Ming-Shiang $\mathrm{Wu}^{1,2}$, for the Taiwan Gastrointestinal Disease and \\ Helicobacter Consortium \\ ${ }^{1}$ Division of Gastroenterology and Hepatology, Department of Internal Medicine, National Taiwan University Hospital, ${ }^{2}$ Department \\ of Internal Medicine, National Taiwan University College of Medicine, ${ }^{3}$ Department of Medicine, National Taiwan University Cancer \\ Center, and ${ }^{4}$ Department of Medical Research, National Taiwan University Hospital, Taipei, Taiwan
}

\section{Article Info}

Received November 7, 2020

Accepted December 14, 2020

Published online March 31, 2021

\section{Corresponding Author}

Jyh-Ming Liou

ORCID https://orcid.org/0000-0002-7945-5408

E-mail jyhmingliou@gmail.com

Jyh-Ming Liou, Yi-Chia Lee, and Ming-Shiang Wu contributed equally to this work as first authors.

\begin{abstract}
The treatment of refractory Helicobacter pylori remains challenging in clinical practice. Factors that should be considered in the treatment of refractory $H$. pylori infection include treatment length, dosage of antibiotics and proton pump inhibitors (PPIs), number of drugs, and the selection of appropriate antibiotics. Extending the treatment length of triple therapy and non-bismuth quadruple therapy to 14 days may increase the eradication rate compared with a shorter period (7 or 10 days). The use of a higher dose of PPIs or vonoprazan may also increase the efficacy of triple therapy. Four-drug therapy, including bismuth or non-bismuth quadruple therapies, usually achieve higher eradication rates than triple therapy. The addition of bismuth or metronidazole to levofloxacin-amoxicillin-PPI therapy may also increase the eradication rate. Therefore, fourdrug therapies containing a higher dose of PPIs for 14 days are recommended in the third-line treatment setting for refractory $H$. pylori infection. The selection of appropriate antibiotics may be guided by susceptibility testing or empirically by medication history. Tailored therapy guided by susceptibility testing or genotypic resistance is recommended whenever possible. However, properly designed empirical therapy based on prior medication history (i.e., avoid the reuse of clarithromycin or levofloxacin empirically) is an acceptable alternative to tailored therapy after considering accessibility, cost, and the preference of the patient. (Gut Liver 2022;16:8-18)
\end{abstract}

Key Words: Helicobacter pylori; Refractory; Third-line; Eradication; Resistance

\section{INTRODUCTION}

Eradication of Helicobacter pylori reduces the recurrence rate of peptic ulcer disease, cures two-thirds of patients with mucosal-associated lymphoid tissue lymphoma, and reduces the risk of gastric cancer. ${ }^{1-4}$ Clarithromycin triple therapy is one of the most commonly used regimen in the first-line treatment. ${ }^{1,5}$ However, the eradication rate of clarithromycin triple therapy is now lower than $80 \%$ in the first-line treatment due to the global rising prevalence of clarithromycin resistance. ${ }^{6,7}$ Levofloxacin triple therapy and bismuth quadruple therapy are the most commonly used second-line rescue regimens. ${ }^{1,5,7,8}$ Yet, about $10 \%$ to $20 \%$ of patients cannot be cured with either one of them. Patients who experience treatment failure after two or more eradication therapies are usually termed as those with refractory $H$. pylori infection. ${ }^{9,10}$ Overall, it is estimated that $3 \%$ to $10 \%$ of $H$. pylori-infected subjects would require third-line rescue therapy for refractory $H$. pylori infection. Yet, treatment of refractory $H$. pylori infection remains a challenge in clinical practice and some patients are left untreated. Therefore, we reviewed current evidence and proposed strategies to optimize the treatment for refractory $H$. pylori infection. 
SHOULD WE RECOMMEND RESCUE THERAPY FOR ALL PATIENTS WITH REFRACTORY H. pylori INFECTION?

There are contradictory viewpoints about whether patients with refractory $H$. pylori infection should be actively treated with rescue therapy or they may be left untreated. Some physicians considered that further rescue therapy is not mandatory because gastric cancer develops only in $1 \%$ to $3 \%$ of $H$. pylori-infected subjects and there are potential concerns about increased risk of antibiotic resistance at individual level as well as in the community. ${ }^{11,12}$ However, most experts considered that physicians should recommend rescue therapy for these patients since eradication of H. pylori reduces the risk of gastric cancer. ${ }^{2,3,47}$ Of course, the patients can make their own decisions according to their preference judging from the benefit and risk of rescue therapy. For example, patients who carry the higher risk of gastric cancer, such as the presence of premalignant lesions and positive family history are candidates for the rescue therapy.

\section{FACTORS ATTRIBUTABLE TO TREATMENT FAILURE}

Physicians should try to identify factors leading to treatment failure for their patients with refractory H. pylori infection. Common reasons for treatment failure include poor compliance to prior treatment, the presence of antibiotic resistance, insufficient delivery of drugs into the gastric mucous layer, rapid metabolism of treatment drugs, and insufficient treatment length. ${ }^{13}$ Poor compliance of therapy may result from adverse effects or the complexity of drug administration of prior regimens. ${ }^{13}$ If the patient's compliance is good, the presence of antibiotic resistance is the most common reason for treatment failure. ${ }^{13}$ The high bacterial load makes it likely that antibiotic-resistant H. pylori strains will be present when antibiotic therapy is begun. The average $H$. pylori-infected stomach contains huge numbers of $H$. pylori such that if the spontaneous rate of development of resistance was only 1 in 10 million and $10^{9}$ (100 million) organisms were present, one would expect that a resistant subpopulation of $H$. pylori would already be present and cause the therapy to fail. ${ }^{4} \mathrm{H}$. pylori can also rapidly acquire new genotypic resistance to many commonly used antimicrobials. Our study showed that the prevalence of clarithromycin resistance was $61 \%$ and $95 \%$ in patients who experienced treatment failures after one and two eradication therapies, respectively. ${ }^{14}$ Another study showed that the gyrase A and 23S rRNA mutant
H. pylori strains were already present in patients who failed after levofloxacin-based and clarithromycin-based triple therapy. ${ }^{15}$ A proportion of $H$. pylori bacteria attach to gastric mucosal cells and form a biofilm, and some are intracellular, which means they are inaccessible to many antibiotics. ${ }^{16}$ This biofilm phenomenon which has been demonstrated with $H$. pylori in vitro and is likely also present in vivo. H. pylori can also survive intracellularly making them inaccessible to topical therapy and to drugs that penetrate cells poorly. ${ }^{16}$ Acetylcystein was shown to destroy the biofilm and may increase the efficacy of eradication therapy for refractory $H$. pylori infection in some studies, but the effect remains controversial. ${ }^{17}$ Most proton pump inhibitors (PPIs) are metabolized through the CYP2C19 pathway and the eradication rate is lower in patients with CYP2C19 extensive metabolizer. ${ }^{18}$ Increase the dosage of PPIs may be required to provide adequate acid suppression and higher eradication rate in such circumstances. ${ }^{18,19}$

OPTIMIZATION OF THIRD-LINE TREATMENT

Optimization of the regimens is important to achieve the best cure rates used in the treatment of refractory $H$. pylori infection. The proposed strategies to optimize the eradication rate are shown in Table 1. These include extending treatment length to 14 days, use of higher dosage or more potent acid suppression agents, optimization of dosage of antibiotics, use of bismuth or non-bismuth quadruple therapy, and selection of appropriate antibiotics according to susceptibility testing or empirically according to detailed medication history. ${ }^{19-26}$

The intragastric location of $H$. pylori complicates therapy as it requires consideration of many variables as the infection is both outside the body, attached to cells, and even within gastric cells. ${ }^{27}$ Factors that should be considered to recommend an optimal regimen include optimum drugs, formulations, routes of administration, doses, dosing intervals, relation to meals, adjuvants, and duration of therapy. ${ }^{27}$ Optimum is defined as the best or most effective therapy possible in a particular situation. In subjects adherent to treatment, regimens are usually expected to achieve cure rates reliably equal to or greater than $95 \%$ for infectious diseases. ${ }^{4,27,28}$

\section{Duration of therapy}

Duration is based on overcoming the persister effect and takes into account that PPIs do not achieve full effectiveness until after 3 or 4 days of administration. ${ }^{4,27,28} \mathrm{Ex}$ tending the treatment length of triple therapy for 14 days was superior to the same regimen given for 7 days or 10 
Table 1. Optimization of Rescue Therapy for Refractory Helicobacter pylori Infection

\begin{tabular}{ll}
\hline \multicolumn{1}{c}{ Strategy } & \\
\hline $\begin{array}{l}\text { Duration of therapy } \\
\text { Dosage of drugs } \\
\text { PPls }\end{array}$ & Higher dosage PPIs (omeprazole $40 \mathrm{mg}$ or equivalent twice daily) or vonoprazan 20 mg twice daily \\
Amoxicillin & $2,000-3,000 \mathrm{mg}$ per day in 2-4 divided doses \\
Levofloxacin & $500 \mathrm{mg}$ per day or 250 mg twice daily \\
Sitafloxacin & $100 \mathrm{mg}$ twice daily \\
Metronidazole & $1,500-1,600 \mathrm{mg}$ per day in 3-4 divided doses \\
Tetracycline & $1,500-2,000 \mathrm{mg}$ per day in 3-4 divided doses \\
Rifabutin & $300 \mathrm{mg}$ per day in 2 divided doses \\
Clarithromycin & $800-1,000$ mg per day in 2 divided doses \\
Number of drugs & We recommended 4-drug therapy (bismuth or non-bismuth quadruple therapy) for refractory H. pylori infection \\
How to choose antibiotics & Guided by susceptibility testing or genotypic resistance whenever possible \\
& Empirical therapy to avoid reuse of clarithromycin and levofloxacin may be an acceptable alternative considering \\
& availability, cost, and preference of patient \\
\hline
\end{tabular}

PPIs, proton pump inhibitors.

days in the first-line treatment. ${ }^{22}$ Thus, various guidelines have recommended duration of 14 days in the first-line treatment unless a shorter duration is locally proven to be non-inferior and produce a reliably high success rate. . $^{1,5,2,29}$ In the second-line or third-line treatment, the cure rates of levofloxacin triple therapy were $58.3 \%, 68.2 \%$, and $93.3 \%$ when the treatment length were 7,10 , and 14 days, respectively. ${ }^{30}$ However, it is noteworthy that the benefit of extending the treatment length to 14 days is minimal in susceptible strains. ${ }^{29}$ However, the eradication rate can be increased in strains with clarithromycin resistance, which is attributable to the effect for PPIs-amoxicillin dual therapy. ${ }^{18}$ Taken together, we recommend 14-day therapy for refractory $H$. pylori infection, but further well designed trials are needed.

\section{Dosage of PPIs}

PPIs vary greatly in relative potency such that it is impossible to compare regimens using different PPIs unless these differences are taken into account. For $H$. pylori eradication, $20 \mathrm{mg}$ omeprazole equivalents, twice daily is regarded as low dose PPI and $40 \mathrm{mg}$ omeprazole equivalents, twice daily regarded as high or double dose. ${ }^{19}$ Randomized trials showed that the use of higher dosage of PPIs may increase the efficacy of triple therapy. ${ }^{24}$ Therefore, it has been recommended to give double dose PPIs because of the benefits obtained by increasing the anti-secretory effect with dual PPIs amoxicillin therapy. More recently, vonoprazan, a potassium-competitive acid blocker, is shown to be more potent than PPIs, especially in those with CYP2C19 extensive metabolizer. Vonoprazanbased triple therapy for 7 days was shown to be superior to lansoprazole-based triple therapy for 7 days in Japanese, especially in those infected with clarithromycin-resistant strains. ${ }^{25} \mathrm{~A}$ recent randomized trial further showed that vonoprazan-based sitafloxacin triple therapy was superior to PPIs-based sitafloxacin triple therapy in the third-line treatment of $H$. pylori infection. ${ }^{31}$

\section{Optimal dosage of antibiotics in rescue therapy}

Earlier studies showed that the use of higher dosage of metronidazole (up to 1,600 to 2,000 mg per day) may partly overcome the metronidazole resistance. ${ }^{13}$ Recent studies also showed that the use of higher dosage of amoxicillin (up to $750 \mathrm{mg}$ three times or four times a day) may increase the efficacy of dual therapy. ${ }^{32}$ The recommended dosage of tetracycline is $500 \mathrm{mg}$ four times a day in bismuth quadruple therapy. ${ }^{1,5,8}$ In contrast, increase in clarithromycin or levofloxacin dosage cannot overcome the resistance to these two antibiotics, respectively.

\section{Number of drugs}

Several randomized trials showed that four-drug regimens, including bismuth quadruple therapy and nonbismuth quadruple therapies (concomitant therapy, sequential therapy, hybrid therapy) were more effective than triple therapy in the first-line treatment when given for the same duration. ${ }^{20,21,23,26}$ Concomitant or sequential therapy for 14 days, but not 10 days, was superior to 14-day triple therapy in the first-line treatment. ${ }^{23,33}$ Triple therapy containing esomeprazole, amoxicillin and metronidazole for 2 weeks was suboptimal in the third-line therapy after failure from clarithromycin-based therapy and fluoroquinolonebased therapy. ${ }^{34}$ The eradication rates were $64 \%$ and $37 \%$ in metronidazole-naive and metronidazole experienced patients, respectively. ${ }^{34}$ Systematic review and meta-analysis showed that the efficacy of levofloxacin triple therapy was lower than $80 \%$ in the second-line treatment. ${ }^{35}$ Hsu et al..$^{36}$ showed that addition of bismuth to levofloxacin triple therapy cured $84 \%$ of patients $(31 / 37)$ in the third-line 


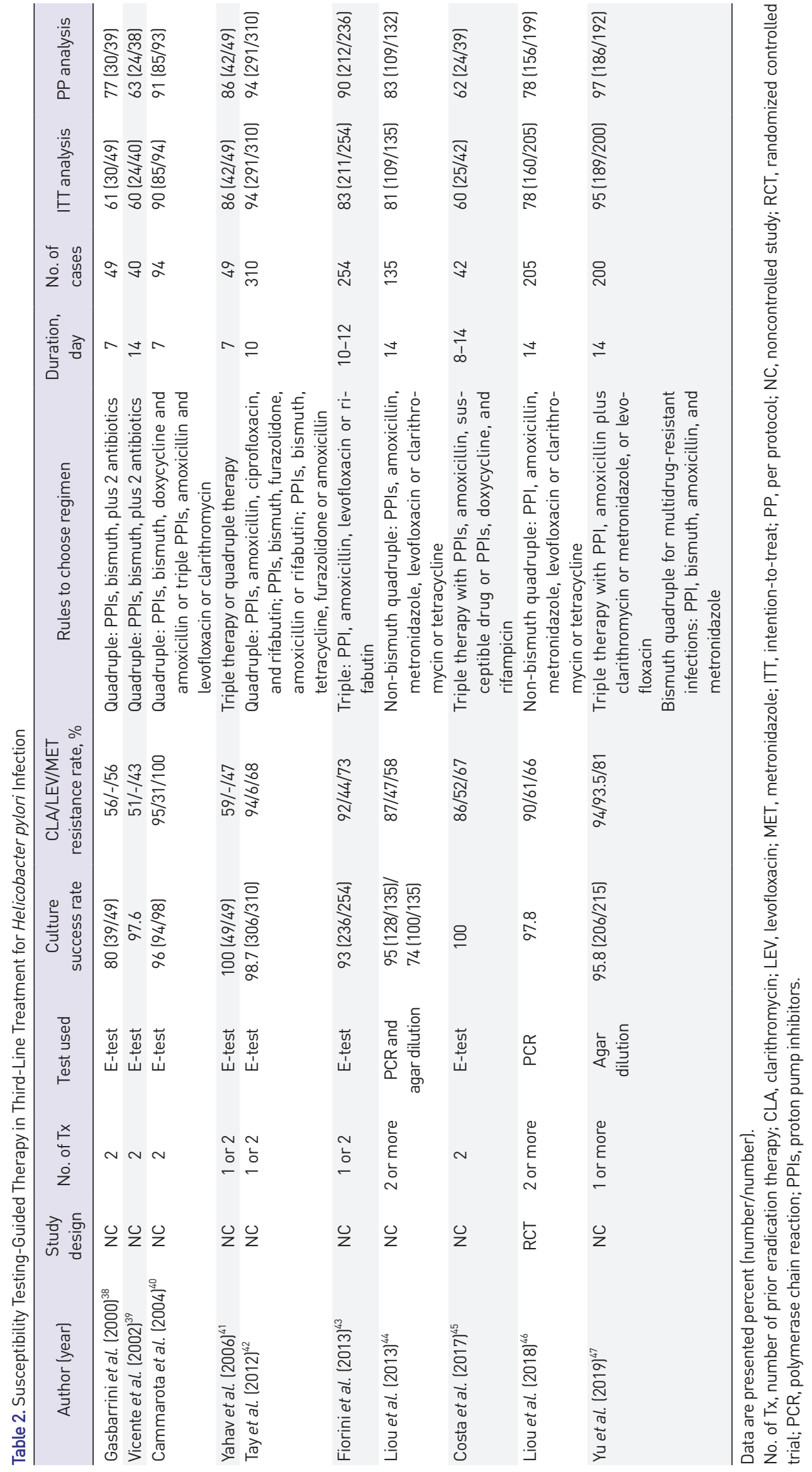


treatment of $H$. pylori infection. The addition of bismuth to rifabutin triple therapy $(96.6 \%, 28 / 29)$ was shown to increase the eradication rate of rifabutin-based triple therapy $(66.7 \%, 18 / 27)$ in the third-line treatment. ${ }^{37}$ Taken together, it is suggested to provide four-drug regimens (bismuth or non-bismuth quadruple therapy) as third-line or fourthline salvage therapy.

\section{How to choose antibiotics in third-line or fourth- line rescue therapies?}

1) Susceptibility guided therapy

Ideally, therapy should be tailored by susceptibility testing whenever possible. Tailored therapy is recommended by international consensus reports for patients with refractory $H$. pylori infection although the evidence level is low for such recommendation. ${ }^{1,4}$ The efficacy of susceptibility testing-guided therapy for refractory $H$. pylori infection has been reported in nine studies, as shown in Table $2 .{ }^{38-47}$ Eight of them are noncontrolled case series, one is non-randomized controlled study, and another one is a randomized control trial. E-test was the most commonly used method to detect antibiotic resistance (Table 2). The successful rate of culture ranged from $74 \%$ to $98 \%$. The resistance rate to clarithromycin, metronidazole, and levofloxacin ranged from $51 \%-95 \%, 43 \%-100 \%$, and $6 \%-52 \%$, respectively. Bismuth quadruple therapy including a PPI, bismuth and another two susceptible antibiotics or nonbismuth quadruple therapy including a PPI plus another three antibiotics were the most commonly used regimens. The treatment length varied from 7 to 14 days. The overall eradication rate of susceptibility testing-guided therapy ranged from $60 \%$ to $90 \%$ (Table 2 ).
However, there is limited evidence to show the superiority of tailored therapy over empirical therapy in rescue therapies. In the first-line therapy, susceptibility testingguided therapy was more effective than empirical triple therapy for 7 or 10 days in the first-line treatment in a meta-analysis of randomized trials. ${ }^{48}$ Yet, two randomized trials showed that empirical bismuth quadruple therapy and empirical non-bismuth quadruple therapy were not inferior to tailored therapy in China and Korea where the clarithromycin-resistant rate was higher than $15 \%$ to $20 \%$. ${ }^{49,50}$ Moreover, tailored therapy was not superior to empirical therapy in three trials that recruited patients failed after one eradication therapy. ${ }^{48}$ Of the only one randomized trial that compared the efficacy of tailored therapy versus empirical therapy for patients who failed after at least two eradication therapies, Liou et al. ${ }^{46}$ showed that the eradication rate of genotypic resistance guided therapy and empirical therapy were $78 \%$ and $72 \%$, respectively. Therefore, our suggestion is that susceptibility testing or genotypic resistance should be determined for patients with refractory $H$. pylori infection whenever possible. However, properly chosen empirical therapy according to the detailed medication history may be an as effective alternative considering accessibility to susceptibility testing, patient preference, and cost.

\section{2) Empirical therapy}

Since the resistance rates are high in patients who fail after regimens containing clarithromycin and levofloxacin, these two antibiotics should not be reused empirically. ${ }^{1,8,51}$ The strategy to choose antibiotics for third-line and fourthline therapy is shown in Fig. 1.,8,51 For patients who have received regimens containing clarithromycin and levoflox-

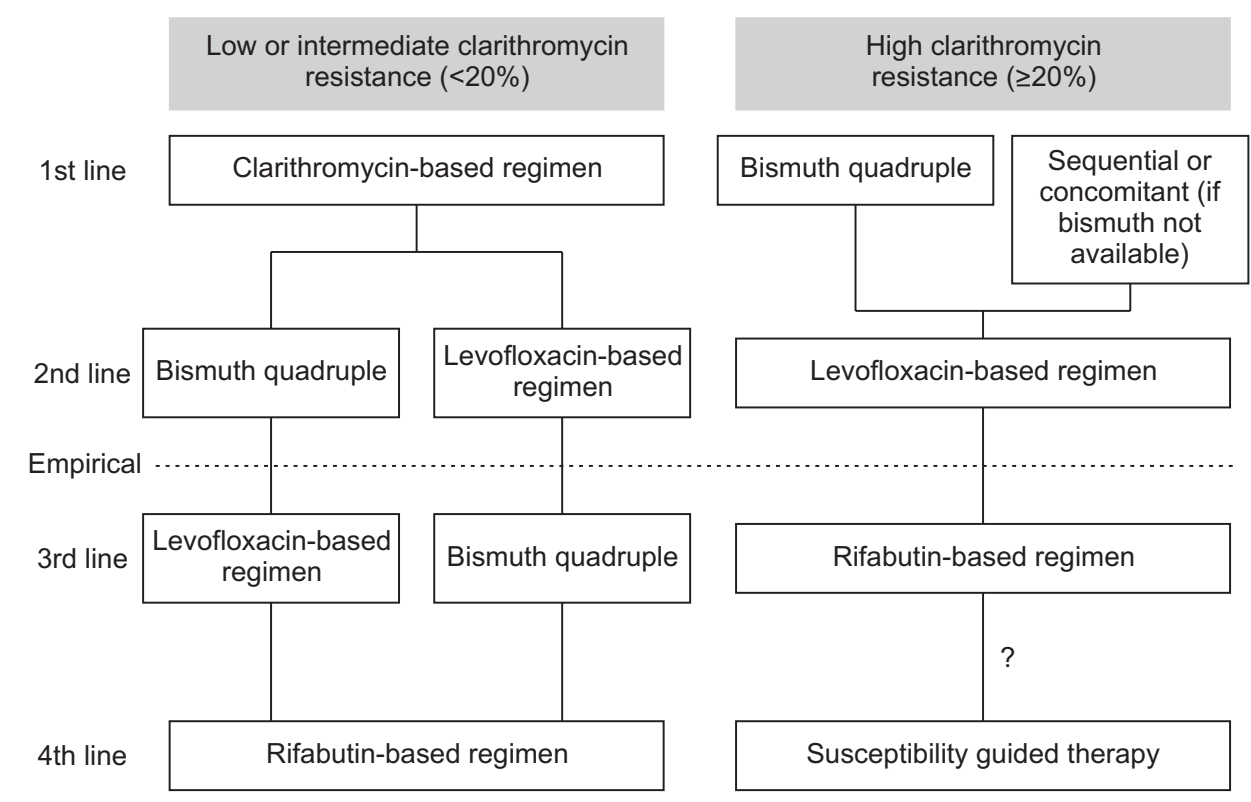

Fig. 1. How to choose antibiotics empirically in rescue therapies. Avoid the reuse of clarithromycin or levofloxacin empirically in third-line rescue treatment.

"?" indicates that although susceptibility testing guided therapy is recommended for patients who fail after a rifabutin-based regimen, there is limited evidence to support this recommendation. 


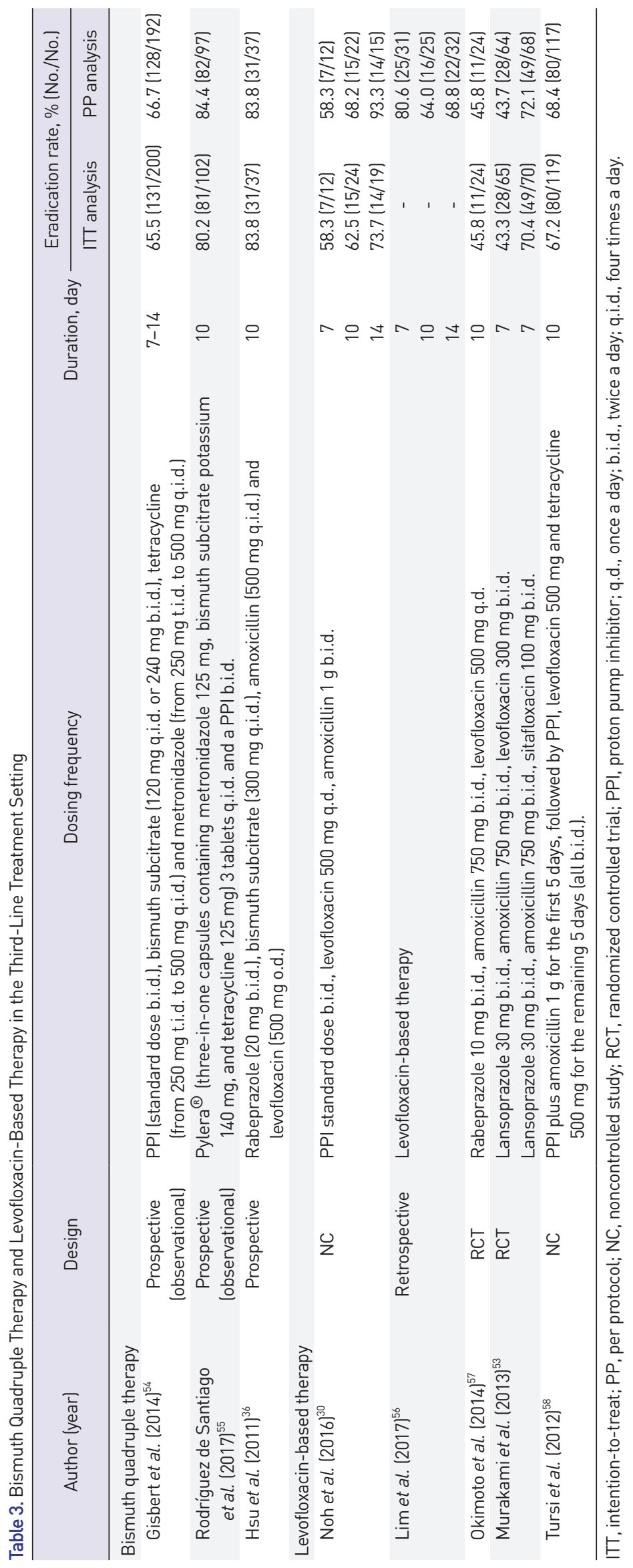


acin in their prior therapies, bismuth quadruple therapy is recommended. For those who have not been treated with levofloxacin-containing regimen in their prior treatment, levofloxacin triple therapy, bismuth enhanced levofloxacin triple therapy, or non-bismuth quadruple therapy containing levofloxacin may be used. For those who have received bismuth quadruple therapy and regimens clarithromycin and levofloxacin in their prior treatments, rifabutin-based triple or quadruple therapy may be used as rescue therapy. Whether re-treatment with bismuth quadruple therapy is an option remains controversial, although a retrospective study in Korea showed that re-treatment with bismuth quadruple therapy cured $75 \%$ of patients who failed after the same regimen in the second-line treatment. ${ }^{52}$ Sitafloxacinbased triple therapy was shown to be effective in patients who harbor gyrase A mutations. ${ }^{53}$ However, there is limited evidence to support the use of sitafloxacin-based therapy for treatment after failure from levofloxacin-based therapy.

There are limited data on the efficacy of empirical bismuth quadruple therapy and levofloxacin-based therapy in the third-line treatment of refractory $H$. pylori infection (Table 3)..$^{30,36,52-57}$ The reported efficacy of 7- to 14day bismuth quadruple therapy containing PPIs, bismuth, tetracycline, and metronidazole varied from $65 \%$ to $80 \%$ in the third-line treatment. ${ }^{54,55}$ The efficacy of 7- to 14-day levofloxacin triple therapy or bismuth enhanced levofloxacin triple therapy ranged from $43.3 \%$ to $84 \%$ in the thirdline treatment (Table 3) ${ }^{30,36,53,56,57}$ The reported efficacy of sitafloxacin-based triple therapy varied from $54 \%$ to $93 \%$ in the third-line treatment (Table 4) ${ }^{53,58-66}$ Meta-analysis of

Table 4. Sitafloxacin Triple Therapy in the Third-Line Treatment Setting

\begin{tabular}{|c|c|c|c|c|c|}
\hline \multirow{2}{*}{ Author lyear) } & \multirow{2}{*}{ Dosing frequency } & \multirow{2}{*}{$\begin{array}{l}\text { Duration, } \\
\text { day }\end{array}$} & \multicolumn{3}{|c|}{ Eradication rate, \% (No./No.) } \\
\hline & & & Overall & Gyrase A wild & Gyrase A mutant \\
\hline Mori et al. (2019) ${ }^{59}$ & $\begin{array}{l}\text { Esomeprazole (20 mg, b.i.d.), amoxicillin ( } 500 \text { mg, q.i.d.), } \\
\text { and sitafloxacin ( } 100 \mathrm{mg} \text {, b.i.d.) }\end{array}$ & 10 & $81.6(31 / 38)$ & $94.7(18 / 19)$ & $68.4(13 / 19)$ \\
\hline \multirow[t]{2}{*}{ Saito et al. $(2019)^{60}$} & $\begin{array}{l}\text { Esomeprazole (20 mg, b.i.d.), amoxicillin (750 mg, b.i.d.), } \\
\text { and sitafloxacin (100 mg, b.i.d.) }\end{array}$ & 7 & $54.2(13 / 24)$ & $66.7(12 / 18)$ & $20.0(1 / 5)$ \\
\hline & $\begin{array}{l}\text { Vonoprazan ( } 20 \text { mg, b.i.d.), amoxicillin ( } 750 \text { mg, b.i.d.), } \\
\text { and sitafloxacin ( } 100 \mathrm{mg} \text {, b.i.d.) }\end{array}$ & 7 & $93.0(53 / 57)$ & $96.4(27 / 28)$ & $91.7(11 / 12)$ \\
\hline \multirow[t]{2}{*}{ Sue et al. $(2019)^{31}$} & $\begin{array}{l}\text { Vonoprazan } 20 \text { mg b.i.d., amoxicillin } 750 \text { mg b.i.d., and } \\
\text { sitafloxacin } 100 \text { mg b.i.d. }\end{array}$ & 7 & $75.8(25 / 33)$ & - & - \\
\hline & $\begin{array}{l}\text { Esomeprazole } 20 \text { mg b.i.d., rabeprazole } 10 \text { mg b.i.d., or } \\
\text { lansoprazole } 30 \text { mg b.i.d.; amoxicillin } 750 \text { mg b.i.d.; } \\
\text { and sitafloxacin } 100 \text { mg b.i.d. }\end{array}$ & 7 & $53.3(16 / 30)$ & - & - \\
\hline Hirata et al. $(2016)^{61}$ & $\begin{array}{l}\text { Esomeprazole } 20 \text { mg b.i.d., amoxicillin } 750 \text { mg b.i.d., } \\
\text { and sitafloxacin } 100 \text { mg b.i.d. }\end{array}$ & 7 & $83.3(25 / 30)$ & - & - \\
\hline \multirow[t]{2}{*}{ Mori et al. $(2016)^{62}$} & $\begin{array}{l}\text { Esomeprazole ( } 20 \text { mg, b.i.d.), amoxicillin (500 mg, q.i.d.), } \\
\text { and sitafloxacin ( } 100 \text { mg, b.i.d.) }\end{array}$ & 10 & $81.0(51 / 63)$ & $100(24 / 24)$ & $70.3(26 / 37)$ \\
\hline & $\begin{array}{l}\text { Esomeprazole ( } 20 \mathrm{mg} \text {, b.i.d.), metronidazole }(250 \mathrm{mg} \text {, } \\
\text { b.i.d.), and sitafloxacin ( } 100 \mathrm{mg} \text {, b.i.d.) }\end{array}$ & 10 & $72.4(42 / 58)$ & $100(16 / 16)$ & $66.7(26 / 39)$ \\
\hline Sugimoto et al. $(2015)^{63}$ & $\begin{array}{l}\text { PPI, amoxicillin } 750 \text { mg b.i.d. and clarithromycin } 200 \text { or } \\
400 \text { mg b.i.d. }\end{array}$ & 7 & $88.3(83 / 94)$ & - & - \\
\hline \multirow[t]{4}{*}{ Furuta et al. $(2014)^{64}$} & $\begin{array}{l}\text { Rabeprazole } 10 \text { mg b.i.d./q.i.d., amoxicillin } 500 \text { mg q.i.d., } \\
\text { and sitafloxacin } 100 \text { mg b.i.d. }\end{array}$ & 7 & $84.1(37 / 44)$ & - & - \\
\hline & $\begin{array}{l}\text { Rabeprazole } 10 \text { mg b.i.d./q.i.d., amoxicillin } 500 \text { mg q.i.d., } \\
\text { and sitafloxacin } 100 \text { mg b.i.d. }\end{array}$ & 14 & $88.9(40 / 45)$ & - & - \\
\hline & $\begin{array}{l}\text { Rabeprazole } 10 \mathrm{mg} \text { b.i.d./q.i.d., metronidazole } 250 \mathrm{mg} \\
\text { b.i.d., and sitafloxacin } 100 \mathrm{mg} \text { b.i.d. }\end{array}$ & 7 & $90.9(40 / 44)$ & - & - \\
\hline & $\begin{array}{l}\text { Rabeprazole } 10 \mathrm{mg} \text { b.i.d./q.i.d., metronidazole } 250 \mathrm{mg} \\
\text { b.i.d., and sitafloxacin } 100 \mathrm{mg} \text { b.i.d. }\end{array}$ & 14 & $87.2(41 / 47)$ & - & - \\
\hline Murakami et al. $(2013)^{53}$ & $\begin{array}{l}\text { LPZ } 30 \text { mg b.i.d. + amoxicillin } 750 \text { mg b.i.d. + sitafloxacin } \\
100 \text { mg b.i.d. }\end{array}$ & 7 & $70.0(49 / 70)$ & $72.0(28 / 39)$ & $50.0(1 / 2)$ \\
\hline Matsuzaki et al. $(2012)^{65}$ & $\begin{array}{l}\text { Rabeprazole (10 mg, q.i.d.), amoxicillin (500 mg, q.i.d.), } \\
\text { and sitafloxacin ( } 100 \text { mg, b.i.d.) }\end{array}$ & 7 & $78.2(61 / 78)$ & $93.5(29 / 31)$ & $68.1(32 / 47)$ \\
\hline Hirata et al. $(2012)^{66}$ & $\begin{array}{l}\text { Rabeprazole } 10 \text { mg b.i.d., amoxicillin } 750 \text { mg b.i.d., and } \\
\text { sitafloxacin } 100 \text { mg b.i.d. }\end{array}$ & 7 & 75.0 (21/28) & $100(1 / 1)$ & $66.7(2 / 3)$ \\
\hline Meta-analysis & & & $\begin{array}{c}80.2 \\
(74.6-84.9) *\end{array}$ & & \\
\hline
\end{tabular}

b.i.d., twice a day; q.i.d., four times a day; PPI, proton pump inhibitor

* $95 \%$ confidence interval. 
these studies revealed that the eradication rate of sitafloxacin-based triple therapy was $80 \%$ (74.6\% to $84.9 \%)$ (Table 4 ). The presence of gyrase A mutation was associated with increased risk of treatment failure (risk ratio, 1.3; 95\% confidence interval, 1.2 to $1.4 ; \mathrm{p}<0.001)$. The eradication rate appeared to be higher when more potent acid secretion inhibitor was used. A randomized trial showed higher efficacy of sitafloxacin-based triple therapy than that of levofloxacin-based triple therapy. ${ }^{53}$ Therefore, sitafloxacin may be preferable to levofloxacin in the treatment of refractory $H$. pylori infection if it is available.

RIFABUTIN-BASED THERAPY IN THE FOURTH-LINE TREATMENT OF H. pylori INFECTION

There are limited data regarding the efficacy of rifabutin-based therapy in the fourth-line treatment. In a prospective noncontrolled trial, Gisbert et al. ${ }^{67}$ showed that rifabutin-based triple therapy containing rifabutin, amoxicillin and PPIs (standard dose twice daily) for 10 days was $50 \%$ (50/100). In another study, Mori et al. ${ }^{68}$ showed that the efficacy of rifabutin-based triple therapy containing esomeprazole ( $20 \mathrm{mg}$, four times a day), amoxicillin (500 $\mathrm{mg}$ four times a day), and rifabutin (300 mg, once daily) in the third-line or fourth-line treatment were $83.3 \%$ (10/12) for the 10-day group and $94.1 \%(16 / 17)$ for the 14 -day group. Therefore, rifabutin-based therapy may be used as the fourth-line rescue treatment empirically for patients who have received clarithromycin-based therapy, levofloxacin-based therapy, and bismuth quadruple therapy in their prior treatments (Fig. 1). ${ }^{37,67,68}$

\section{CONCLUSIONS}

In conclusion, four-drug therapies containing higher dosage of PPIs for 14 days are recommended in the thirdline treatment of refractory $H$. pylori infection. Susceptibility testing or genotypic resistance guided therapy is recommended whenever possible. However, properly designed empirical therapy, based on prior medication history (i.e., avoid reuse of clarithromycin or levofloxacin empirically), is an acceptable alternative to susceptibility testingguided therapy after consideration of accessibility, cost, and preference of patient. Rifabutin-based therapy may be used as the fourth-line rescue therapy for those who have previously been treated with clarithromycin-based therapy, levofloxacin or sitafloxacin-based therapy, and bismuth quadruple therapy. Further large scale, randomized trials are warranted to identify the best strategy in the treatment of refractory $H$. pylori infection.

\section{CONFLICTS OF INTEREST}

No potential conflict of interest relevant to this article was reported.

\section{ACKNOWLEDGEMENTS}

The authors received grants from the Ministry of Science and Technology (grant number: TCTC 109-2321-B002-035 and MOST 108-2314-B-002-187, 109-2314-B002-090-MY3, 109-2314-B-002-202), the Ministry of Health and Welfare (grant number: MOHW109-TDUB-211-114002, MOHW109-CDC-C-114-122118), "Center of Precision Medicine" from The Featured Areas Research Center Program within the framework of the Higher Education Sprout Project by the Ministry of Education (MOE) (grant number: NTU-109L901401), National Taiwan University Hospital (grant number: NTUH 109-P05), and the Liver Disease Prevention \& Treatment Research Foundation, Taiwan. The funding source had no role in study design, data collection, analysis or interpretation, report writing or the decision to submit this paper for publication.

The authors would like to express their special thanks to the staff of the Eighth Core Lab, Department of Medical Research, National Taiwan University Hospital and members of Taiwan Gastrointestinal Diseases and Helicobacter Consortium for their technological support.

\section{ORCID}

Jyh-Ming Liou https://orcid.org/0000-0002-7945-5408 Yi-Chia Lee https://orcid.org/0000-0002-8160-1216 Ming-Shiang Wu https://orcid.org/0000-0002-1940-6428

\section{REFERENCES}

1. Malfertheiner P, Megraud F, O'Morain CA, et al. Management of Helicobacter pylori infection: the Maastricht V/ Florence Consensus Report. Gut 2017;66:6-30.

2. Lee YC, Chiang TH, Chou CK, et al. Association between Helicobacter pylori eradication and gastric cancer incidence: a systematic review and meta-analysis. Gastroenterology 2016;150:1113-1124.

3. Liou JM, Lee YC, El-Omar EM, Wu MS. Efficacy and long- 
term safety of $\mathrm{H}$. pylori eradication for gastric cancer prevention. Cancers (Basel) 2019;11:593.

4. Liou JM, Malfertheiner P, Lee YC, et al. Screening and eradication of Helicobacter pylori for gastric cancer prevention: the Taipei global consensus. Gut 2020;69:2093-2112.

5. Graham DY. Helicobacter pylori update: gastric cancer, reliable therapy, and possible benefits. Gastroenterology 2015;148:719-731.

6. Kuo YT, Liou JM, El-Omar EM, et al. Primary antibiotic resistance in Helicobacter pylori in the Asia-Pacific region: a systematic review and meta-analysis. Lancet Gastroenterol Hepatol 2017;2:707-715.

7. Liou JM, Lin JT, Chang CY, et al. Levofloxacin-based and clarithromycin-based triple therapies as first-line and second-line treatments for Helicobacter pylori infection: a randomised comparative trial with crossover design. Gut 2010;59:572-578.

8. Fallone CA, Chiba N, van Zanten SV, et al. The Toronto Consensus for the treatment of Helicobacter pylori infection in adults. Gastroenterology 2016;151:51-69.

9. Liou JM, Bair MJ, Chen CC, et al. Levofloxacin sequential therapy vs levofloxacin triple therapy in the second-line treatment of Helicobacter pylori: a randomized trial. Am J Gastroenterol 2016;111:381-387.

10. Liou JM, Chen CC, Chen MJ, et al. Empirical modified sequential therapy containing levofloxacin and high-dose esomeprazole in second-line therapy for Helicobacter pylori infection: a multicentre clinical trial. J Antimicrob Chemother 2011;66:1847-1852.

11. Blaser MJ. Antibiotic use and its consequences for the normal microbiome. Science 2016;352:544-545.

12. Liou JM, Chen CC, Chang CM, et al. Long-term changes of gut microbiota, antibiotic resistance, and metabolic parameters after Helicobacter pylori eradication: a multicentre, open-label, randomised trial. Lancet Infect Dis 2019;19:1109-1120.

13. Vakil N, Megraud F. Eradication therapy for Helicobacter pylori. Gastroenterology 2007;133:985-1001.

14. Liou JM, Chang CY, Chen MJ, et al. The primary resistance of Helicobacter pylori in Taiwan after the national policy to restrict antibiotic consumption and its relation to virulence factors: a nationwide study. PLoS One 2015;10:e0124199.

15. Liou JM, Chang CY, Sheng WH, et al. Genotypic resistance in Helicobacter pylori strains correlates with susceptibility test and treatment outcomes after levofloxacin- and clarithromycin-based therapies. Antimicrob Agents Chemother 2011;55:1123-1129.

16. Cammarota G, Sanguinetti M, Gallo A, Posteraro B. Review article: biofilm formation by Helicobacter pylori as a target for eradication of resistant infection. Aliment Pharmacol Ther 2012;36:222-230.
17. Fontes LES, Martimbianco ALC, Zanin C, Riera R. Nacetylcysteine as an adjuvant therapy for Helicobacter pylori eradication. Cochrane Database Syst Rev 2019;2:CD012357.

18. Graham DY. Hp-normogram (normo-graham) for assessing the outcome of $\mathrm{H}$. pylori therapy: effect of resistance, duration, and CYP2C19 genotype. Helicobacter 2016;21:85-90.

19. Graham DY, Lu H, Dore MP. Relative potency of protonpump inhibitors, Helicobacter pylori therapy cure rates, and meaning of double-dose PPI. Helicobacter 2019;24:e12554.

20. Liou JM, Chen CC, Chen MJ, et al. Sequential versus triple therapy for the first-line treatment of Helicobacter pylori: a multicentre, open-label, randomised trial. Lancet 2013;381:205-213.

21. Liou JM, Chen CC, Chang CY, et al. Sequential therapy for 10 days versus triple therapy for 14 days in the eradication of Helicobacter pylori in the community and hospital populations: a randomised trial. Gut 2016;65:1784-1792.

22. Yuan Y, Ford AC, Khan KJ, et al. Optimum duration of regimens for Helicobacter pylori eradication. Cochrane Database Syst Rev 2013;(12):CD008337.

23. Liou JM, Fang YJ, Chen CC, et al. Concomitant, bismuth quadruple, and 14-day triple therapy in the first-line treatment of Helicobacter pylori: a multicentre, open-label, randomised trial. Lancet 2016;388:2355-2365.

24. McNicholl AG, Linares PM, Nyssen OP, Calvet X, Gisbert JP. Meta-analysis: esomeprazole or rabeprazole vs. firstgeneration pump inhibitors in the treatment of Helicobacter pylori infection. Aliment Pharmacol Ther 2012;36:414-425.

25. Murakami K, Sakurai Y, Shiino M, Funao N, Nishimura A, Asaka M. Vonoprazan, a novel potassium-competitive acid blocker, as a component of first-line and second-line triple therapy for Helicobacter pylori eradication: a phase III, randomised, double-blind study. Gut 2016;65:1439-1446.

26. Liou JM, Chen CC, Fang YJ, et al. 14 day sequential therapy versus 10 day bismuth quadruple therapy containing highdose esomeprazole in the first-line and second-line treatment of Helicobacter pylori: a multicentre, non-inferiority, randomized trial. J Antimicrob Chemother 2018;73:25102518.

27. Graham DY. Antibiotic resistance in Helicobacter pylori: implications for therapy. Gastroenterology 1998;115:12721277.

28. Graham DY, Tansel A. Interchangeable use of proton pump inhibitors based on relative potency. Clin Gastroenterol Hepatol 2018;16:800-808.

29. Liou JM, Chen PY, Kuo YT, Wu MS; Taiwan Gastrointestinal Disease and Helicobacter Consortium. Toward population specific and personalized treatment of Helicobacter pylori infection. J Biomed Sci 2018;25:70.

30. Noh HM, Hong SJ, Han JP, et al. Eradication rate by duration of third-line rescue therapy with levofloxacin after Helico- 
bacter pylori treatment failure in clinical practice. Korean J Gastroenterol 2016;68:260-264.

31. Sue S, Shibata W, Sasaki T, et al. Randomized trial of vonoprazan-based versus proton-pump inhibitor-based thirdline triple therapy with sitafloxacin for Helicobacter pylori. J Gastroenterol Hepatol 2019;34:686-692.

32. Yang JC, Lin CJ, Wang HL, et al. High-dose dual therapy is superior to standard first-line or rescue therapy for Helicobacter pylori infection. Clin Gastroenterol Hepatol 2015;13:895-905.

33. Chen MJ, Chen CC, Chen YN, et al. Systematic review with meta-analysis: concomitant therapy vs. triple therapy for the first-line treatment of Helicobacter pylori infection. Am J Gastroenterol 2018;113:1444-1457.

34. Puig I, González-Santiago JM, Molina-Infante J, et al. Fourteen-day high-dose esomeprazole, amoxicillin and metronidazole as third-line treatment for Helicobacter pylori infection. Int J Clin Pract 2017;71:e13004.

35. Chen PY, Wu MS, Chen CY, et al. Systematic review with meta-analysis: the efficacy of levofloxacin triple therapy as the first- or second-line treatments of Helicobacter pylori infection. Aliment Pharmacol Ther 2016;44:427-437.

36. Hsu PI, Wu DC, Chen A, et al. Quadruple rescue therapy for Helicobacter pylori infection after two treatment failures. Eur J Clin Invest 2008;38:404-409.

37. Ciccaglione AF, Tavani R, Grossi L, Cellini L, Manzoli L, Marzio L. Rifabutin containing triple therapy and rifabutin with bismuth containing quadruple therapy for third-line treatment of Helicobacter pylori infection: two pilot studies. Helicobacter 2016;21:375-381.

38. Gasbarrini A, Ojetti V, Armuzzi A, et al. Efficacy of a multistep strategy for Helicobacter pylori eradication. Aliment Pharmacol Ther 2000;14:79-83.

39. Vicente R, Sicilia B, Gallego S, Revillo MJ, Ducóns J, Gomollón F. Helicobacter pylori eradication in patients with peptic ulcer after two treatment failures: a prospective cultureguided study. Gastroenterol Hepatol 2002;25:438-442.

40. Cammarota G, Martino A, Pirozzi G, et al. High efficacy of 1-week doxycycline- and amoxicillin-based quadruple regimen in a culture-guided, third-line treatment approach for Helicobacter pylori infection. Aliment Pharmacol Ther 2004;19:789-795.

41. Yahav J, Samra Z, Niv Y, et al. Susceptibility-guided vs. empiric retreatment of Helicobacter pylori infection after treatment failure. Dig Dis Sci 2006;51:2316-2321.

42. Tay CY, Windsor HM, Thirriot F, et al. Helicobacter pylori eradication in Western Australia using novel quadruple therapy combinations. Aliment Pharmacol Ther 2012;36:10761083.

43. Fiorini G, Vakil N, Zullo A, et al. Culture-based selection therapy for patients who did not respond to previous treat- ment for Helicobacter pylori infection. Clin Gastroenterol Hepatol 2013;11:507-510.

44. Liou JM, Chen CC, Chang CY, et al. Efficacy of genotypic resistance-guided sequential therapy in the third-line treatment of refractory Helicobacter pylori infection: a multicentre clinical trial. J Antimicrob Chemother 2013;68:450-456.

45. Costa S, Soares JB, Gonçalves R. Efficacy and tolerability of culture-guided treatment for Helicobacter pylori infection. Eur J Gastroenterol Hepatol 2017;29:1258-1263.

46. Liou JM, Chen PY, Luo JC, et al. Efficacies of genotypic resistance-guided vs empirical therapy for refractory Helicobacter pylori infection. Gastroenterology 2018;155:11091119.

47. Yu L, Luo L, Long X, et al. Susceptibility-guided therapy for Helicobacter pylori infection treatment failures. Therap Adv Gastroenterol 2019;12:1756284819874922.

48. López-Góngora S, Puig I, Calvet X, et al. Systematic review and meta-analysis: susceptibility-guided versus empirical antibiotic treatment for Helicobacter pylori infection. J Antimicrob Chemother 2015;70:2447-2455.

49. Chen Q, Long X, Ji Y, et al. Randomised controlled trial: susceptibility-guided therapy versus empiric bismuth quadruple therapy for first-line Helicobacter pylori treatment. Aliment Pharmacol Ther 2019;49:1385-1394.

50. Ong S, Kim SE, Kim JH, et al. Helicobacter pylori eradication rates with concomitant and tailored therapy based on $23 \mathrm{~S}$ rRNA point mutation: a multicenter randomized controlled trial. Helicobacter 2019;24:e12654.

51. Liou JM, Lee YC, Wu MS. Treatment of Helicobacter pylori infection and its long-term impacts on gut microbiota. J Gastroenterol Hepatol 2020;35:1107-1116.

52. Lee SK, Lee SW, Park JY, et al. Effectiveness and safety of repeated quadruple therapy in Helicobacter pylori infection after failure of second-line quadruple therapy: repeated quadruple therapy as a third-line therapy. Helicobacter 2011;16:410-414.

53. Murakami K, Furuta T, Ando T, et al. Multi-center randomized controlled study to establish the standard third-line regimen for Helicobacter pylori eradication in Japan. J Gastroenterol 2013;48:1128-1135.

54. Gisbert JP, Perez-Aisa A, Rodrigo L, et al. Third-line rescue therapy with bismuth-containing quadruple regimen after failure of two treatments (with clarithromycin and levofloxacin) for H. pylori infection. Dig Dis Sci 2014;59:383-389.

55. Rodríguez de Santiago E, Martín de Argila de Prados C, Marcos Prieto HM, et al. Limited effectiveness with a 10-day bismuth-containing quadruple therapy (Pylera ${ }^{\oplus}$ ) in thirdline recue treatment for Helicobacter pylori infection. A reallife multicenter study. Helicobacter 2017;22:e12423.

56. Lim JH, Kim SG, Song JH, et al. Efficacy of levofloxacinbased third-line therapy for the eradication of Helicobacter 
pylori in peptic ulcer disease. Gut Liver 2017;11:226-231.

57. Okimoto K, Arai M, Saito K, et al. Efficacy of levofloxacin based triple and high-dose PPI-amoxicillin dual eradication therapy for Helicobacter pylori after failures of first- and second-line therapies. Int Sch Res Notices 2014;2014:631501.

58. Tursi A, Picchio M, Elisei W. Efficacy and tolerability of a third-line, levofloxacin-based, 10-day sequential therapy in curing resistant Helicobacter pylori infection. J Gastrointestin Liver Dis 2012;21:133-138.

59. Mori H, Suzuki H, Matsuzaki J, Masaoka T, Kanai T. 10-Year trends in Helicobacter pylori eradication rates by sitafloxacin-based third-line rescue therapy. Digestion 2020;101:644650.

60. Saito Y, Konno K, Sato M, et al. Vonoprazan-based third-line therapy has a higher eradication rate against sitafloxacinresistant Helicobacter pylori. Cancers (Basel) 2019;11:116.

61. Hirata Y, Serizawa T, Shichijo S, et al. Efficacy of triple therapy with esomeprazole, amoxicillin, and sitafloxacin as a third-line Helicobacter pylori eradication regimen. Int J Infect Dis 2016;51:66-69.

62. Mori H, Suzuki H, Matsuzaki J, et al. Efficacy of 10-day sitafloxacin-containing third-line rescue therapies for Helicobacter pylori strains containing the gyrA mutation. Helicobacter 2016;21:286-294.
63. Sugimoto M, Sahara S, Ichikawa H, Kagami T, Uotani T, Furuta T. High Helicobacter pylori cure rate with sitafloxacinbased triple therapy. Aliment Pharmacol Ther 2015;42:477483.

64. Furuta T, Sugimoto M, Kodaira C, et al. Sitafloxacin-based third-line rescue regimens for Helicobacter pylori infection in Japan. J Gastroenterol Hepatol 2014;29:487-493.

65. Matsuzaki J, Suzuki H, Nishizawa T, et al. Efficacy of sitafloxacin-based rescue therapy for Helicobacter pylori after failures of first- and second-line therapies. Antimicrob Agents Chemother 2012;56:1643-1645.

66. Hirata Y, Ohmae T, Yanai A, et al. Sitafloxacin resistance in Helicobacter pylori isolates and sitafloxacin-based triple therapy as a third-line regimen in Japan. Int J Antimicrob Agents 2012;39:352-355.

67. Gisbert JP, Castro-Fernandez M, Perez-Aisa A, et al. Fourthline rescue therapy with rifabutin in patients with three Helicobacter pylori eradication failures. Aliment Pharmacol Ther 2012;35:941-947.

68. Mori H, Suzuki H, Matsuzaki J, et al. Rifabutin-based 10day and 14-day triple therapy as a third-line and fourth-line regimen for Helicobacter pylori eradication: a pilot study. United European Gastroenterol J 2016;4:380-387. 